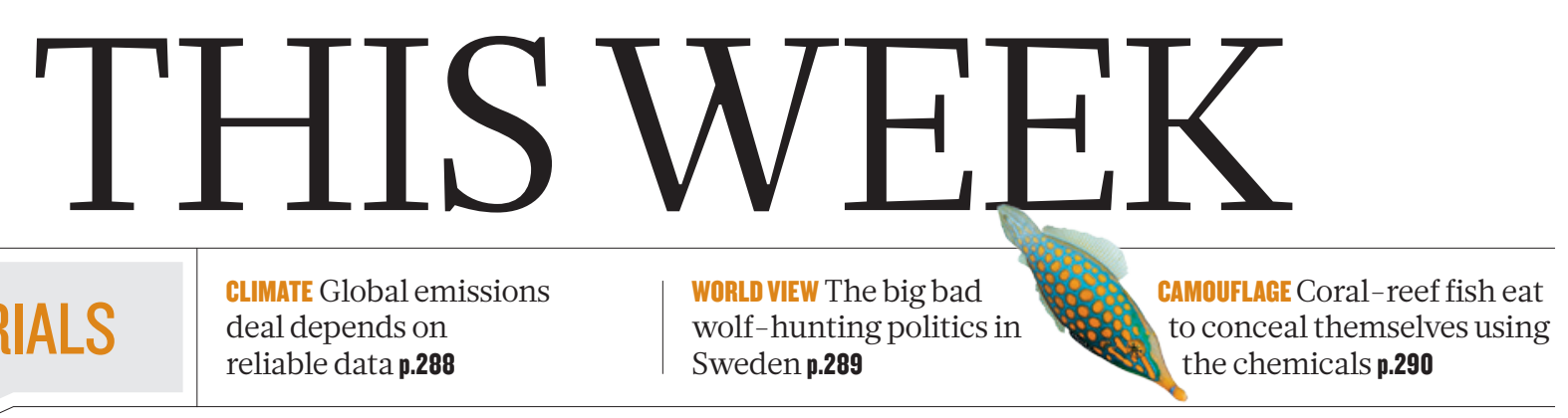

EDITORIALS deal depends on reliable data $\mathbf{p . 2 8 8}$

wolf-hunting politics in Sweden $\mathbf{p . 2 8 9}$
CAMOUFLAGE Coral-reef fish eat the chemicals $\mathbf{p . 2 9 0}$

\title{
Keep asking the question
}

\author{
Scientists must push to preserve a small part of a large US survey that provides essential \\ information on the ever-changing scientific workforce.
}

S ome 3.5 million households in the United States receive a survey each year with six dozen or so questions from the US Census Bureau. Among enquiries about occupation, income, household plumbing, commute times, ethnicity and more is 'Person Question 12 ', which asks university graduates what subject they studied. This census question, along with six others, may be dropped from future surveys as part of a push to streamline federal data collection. That would be a big mistake.

Data from question 12 are used by several studies of higher education, to assess, for example, how degree subjects correlate with unemployment and earnings. If the question is dropped, that information will be lost - or produced only at greater cost. Nature's readers can help to make sure that does not happen.

The question features on the American Community Survey, an ongoing mandatory survey launched in 2005 to provide timelier data than the more-intense decadal countrywide census. Faced with criticism from some legislators that the annual survey is a public imposition, officials reviewed all its questions to see how much time they required, how difficult or sensitive respondents found them, and how federal agencies used the data.

Asking about degrees posed a minimal burden on respondents, the review concluded. But the question was also deemed to be one of a few not required by statute or by regulatory agencies. (Alongside, for example, a question that asks whether US citizens have a medical facility on their property.) So, it faces the chop.

Why should it be kept? Difficult times for scientists make such data more important than ever. On 10 December, the National Academies released a long-awaited report on the postdoctoral experience. It decried the increasing fraction of $\mathrm{PhD}$-holders taking these positions by default, and on academia's still-increasing treatment of postdocs as cheap labour rather than as trainees. Two weeks ago, this journal described two reports on the plight of postdocs and freshly minted science $\mathrm{PhD}$ graduates in the United States and the United Kingdom (see Nature 516, $7-8$; 2014). Both reached similar conclusions: although an academic career is still presented as the default path, only a tiny minority (perhaps less than 5\%) of new science PhDs will go on to permanent academic research positions. These reports stressed the need for more data to keep track of scientific (and non-scientific) careers.

The information that is available on the US situation is most conveniently presented in regular reports produced by the National Science Foundation (NSF). These include the biennial Science and Engineering Indicators and statistics about the participation and attainment of women, under-represented minorities, immigrants and disabled people. The reports reveal trends and disparities, such as the continuing dearth of women in computational science. They also aid international studies of the scientific workforce.

Congressional mandates demand that the NSF produces such reports. Before question 12 was introduced by the census bureau, the

agency had to carry out its own survey to acquire the information that the responses provide. It cost US\$17 million in 2003. Today, that effort would be even more costly and less effective. The workforce is increasingly mobile. People in scientific careers shift jobs so frequently that workforce scholars now refer to career pathways instead of pipelines. Building a sampling pool from the decennial census data would miss the hordes of people moving in and out of relevant fields as well as in and out of the country.

Scientists across the world are starting to realize the power and value of increasing efforts to study and foster its workforce. Uni-

"On a survey estimated to take 40 minutes to complete, question 12 requires only nine seconds." that means that less-intense population surveys are not big enough to get appropriate samples.

On a survey estimated to take 40 minutes to complete, question 12 requires only nine seconds. There is little to gain in its elimination and much to lose. Scientists and their allies should not only argue to retain the question, but also that the census bureau should recognize it as legally required in light of the NSF's mandates. The call for public comments on its removal ends on 30 December (see go.nature.com/ceqkkl). A robust response could encourage the administration to keep it. $\square$

\section{Spin cycle}

\section{Pressures in all stages of the news-making} process can lead to hype in science reporting.

I thas become popular for people to receive, on landmark birthdays, a copy of a daily newspaper from the day of their birth. Someone born today, should they receive such a present in the future, may well wonder what on Earth they have in their hands.

The death of the printed daily paper has been much discussed. But the life of the printed daily paper is a curious thing, too: an entire existence predicated on the lie that the world has changed so much since the previous day that readers must pay for an instant briefing that they can hold in their hands. The same applies the following day, the day after that and so on. 